\title{
Experimental and Simulant Study on Vertical U-Tube Underground Heat Exchanger in Ground-Source Heat Pump
}

\author{
Zhen $\mathrm{Gao}^{1,2}$, Jinwei $\mathrm{Ma}^{1,3}$, Xiaochun $\mathrm{Yu}^{1,2}$, Yu Zhang ${ }^{1,3}$, Ning $\mathrm{Hu}^{1,3}$ and Yanping \\ Wang $^{1,3, a}$
}
1. Anhui Advanced Technology Research Institute of Green Building, Anhui Jianzhu University, Hefei 230601, China;

2. Chinese Hefei Railway Constrction Real Estate Group C.O.. Ltd, Hefei 230041, China;

3. College of Environment and Energy Engineering, Anhui Jianzhu University, Hefei 230601, China.

aEmail:267284143@qq.com

Keywords: ground-source heat pump system; vertical U-tube underground heat exchangers; simulation and analysis; ANSYS

\begin{abstract}
Combined with the ground-source heat pump engineering in Hefei, a 100-meter-deep vertical u-shaped buried pipe was analyzed, and the experimental study on the heat transfer performance of different operating mode, the unit energy efficiency and the change of soil temperature field was taken under a typical climate condition in the summer of Hefei. The change of soil temperature field around the heat exchanger after running for a long time was simulated and analyzed. The results show that soil temperature increased by $1.2{ }^{\circ} \mathrm{C}$ after the system ran for 5 years .
\end{abstract}

\section{Introduction}

Ground-source heat pump is based on surface energy for heat source (or heat sink). It's the real "green energy", and can transfer low-grade thermal energy to the high-grade heat energy by putting in a small amount of high-grade energy. Shuhong Li et.al studied the heat transfer characteristics, and the soil temperature around the underground heat exchangers was simulated under a typical climatic condition of the Yangtze River. The results show that the soil temperature around the underground tube keeps increasing due to the surplus heat ejecting into the earth in summer, which deteriorates the system performance and may lead to the eventual system deterioration[1]. Weibo Yang et.al proposed and developed an updated two-region vertical U-tube GHE analytical model, which is fit for system dynamic simulation of GCHP. It divides the heat transfer region of GHE into two parts at the boundary of borehole wall, and the two regions are coupled by the temperature of borehole wall. Both steady and transient heat transfer method are used to analyze the heat transfer process inside and outside borehole respectively[2].Lyman et al. performed experimental studies on different louver models with varied fin pitch and louver angles over a range of Reynolds numbers. This study presented a method for evaluating spatially resolved louver heat transfer coefficients [3].Hikmet Esen et.al demonstrated the comparison of an artificial neural network (ANN) and an adaptive neuro-fuzzy inference system (ANFIS) for the prediction performance of a vertical ground source heat pump (VGSHP) system. The VGSHP system using R-22 as refrigerant has a three single U-tube ground heat exchanger(GHE), made of polyethylene pipe with an outside diameter of $40 \mathrm{~mm}$. The GHEs were placed in a vertical boreholes (VBs) with 30m (VB1), 60m (VB2) and 90m 
(VB3) depths and 150mm diameters[4].Yuehong $\mathrm{Bi}$ et.al designed the underground two-dimensional symmetry temperature field of a vertical double spiral coil ground heat exchanger (GHX) for a ground source heat pump (GSHP) system was simulated using the volume-control method. The analytical results are compared thoroughly with the experimental data. The mathematical mode presented herein may provide design guidance for the design of GHX for GSHP systems[5]. Gehlin et.al describes a simulation-based study of design flow velocities for a ground-source heat pump system in a heating dominated climate - Sioux Tails, South Dakota. The effect of pipe diameter and Reynolds number are investigated and the effects on system performance and head loss are analyzed[6]. Erhan et al. evaluated the performance of horizontal GSHP by considering various system parameters for winter climatic condition of Bursa, Turkey, and the results showed that the GSHP system was more cost-effective than all the other conventional heating systems[7]. Compared with traditional air conditioning system, the main difference of ground source heat pump air conditioning system is that it adds a geothermal heat exchanger, namely loop of buried pipes. There is no serious difference between it and the building air conditioning system. Therefore, the key is the underground-buried pipe heat exchanger for ground-source heat pump system. Its performance is directly related to the efficiency of the whole system. This paper intends to analyze the heat transfer performance of ground heat exchanger and the change of soil temperature field around the heat exchanger under different operation modes, and simulation operation condition and soil temperature field for a long time about buried tube heat exchanger.

\section{Project profile}

This project is for the China railway - Qing Xiu City sales offices. The total construction area is $3339 \mathrm{~m}^{2}$, a total of four layers (the ground floor and the other three floors on it). The ground floor area is $908 \mathrm{~m}^{2}$, and $2431 \mathrm{~m}^{2}$ on the ground. Air conditioning design cooling load is $420 \mathrm{~kW}$, as heating load is $380 \mathrm{~kW}$. Cold and heat source of the project is Ground Source Heat Pump system, and the end of the system is fan coil plus fresh air.

\section{Experimental research and analysis}

There is unsteady-state heat transfer process between the buried tube and the backfilled material, when heat pump units continuously running, the heat was absorbed or released by the soil constantly, so temperature of the soil was changing. The soil temperature changes greatly with the system running continuously, so the performance of the heat exchanger declines and performance coefficient of the heat pump decreases. The project in this paper belongs to office building, so operation of the system is non-continuously. It is helpful to the thermal balance of underground soil, and it is beneficial to the operation performance of unit and long-term stable operation of the system.

The author has carried on the experiment in winter in late December and early January 2014. Relative location of buried pipe arrangement is shown in Fig. 1. Drilling the number 84, and effective depth of 100 meters and spacing of 4 meters, covers an area of about $1300 \mathrm{~m}^{2}$. Buried tube heat exchanger with DN25 double U PE pipe, the hole diameter of $150 \mathrm{~mm}$, drilling back filler used fine sand. Among them, K1 and K41 were test wells. Experiment system schematic diagram was shown in Fig. 2. 


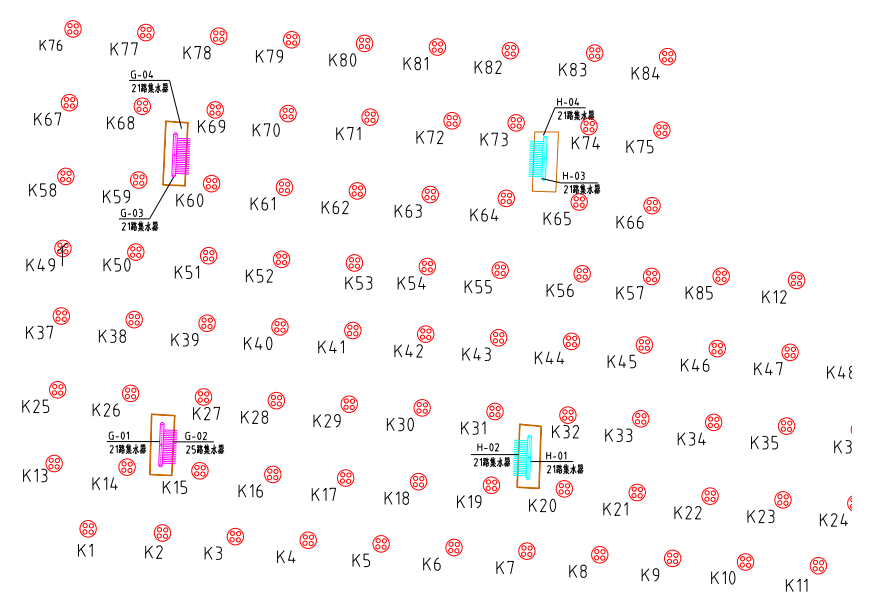

Figure 1 Relative locations of the heat exchanger

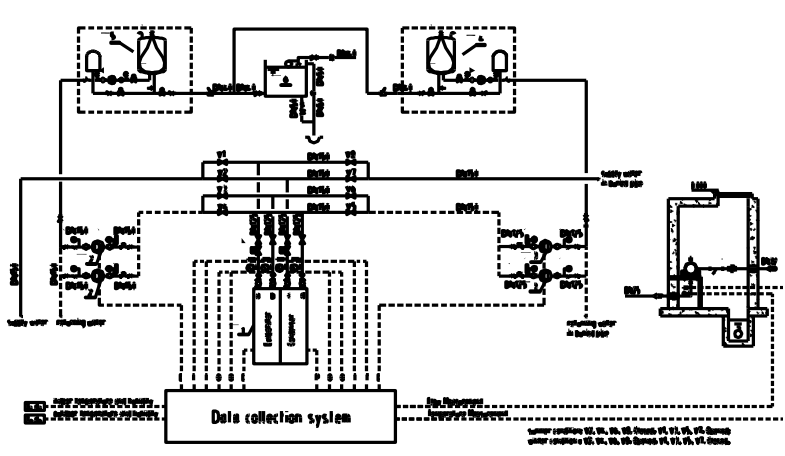

Figure 2 The principle diagram of the experimental system

\section{The original test at low temperature}

During the period of July 25 to 31 , the original ground temperature was tested after the laboratory was built and debugged. The test data is shown in Fig. 3. According to Fig. 3, it can be seen that the deeper into the ground, the soil temperature variation is smaller. Soil temperature variation curve has a smaller range of fluctuations in the ground $5 \mathrm{~m}$. This is advantageous to the heat transfer.

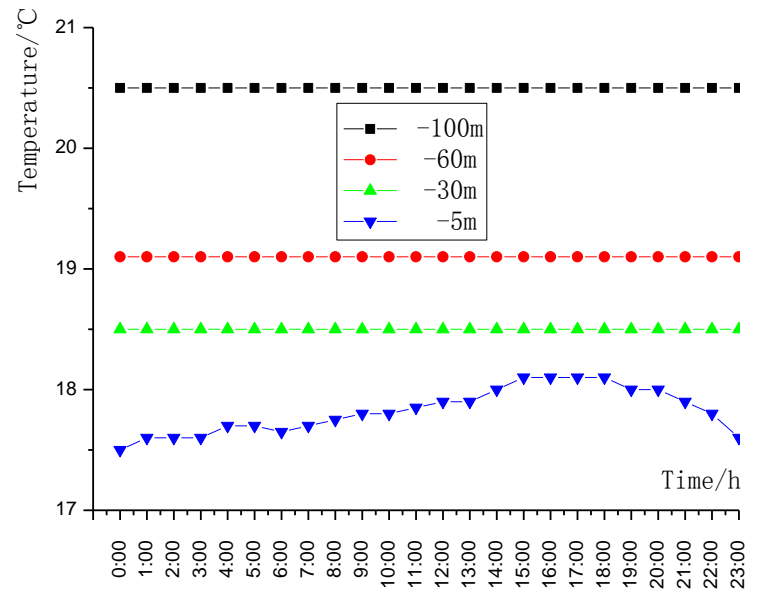

Figure 3 Soil of different depth underground temperature distribution

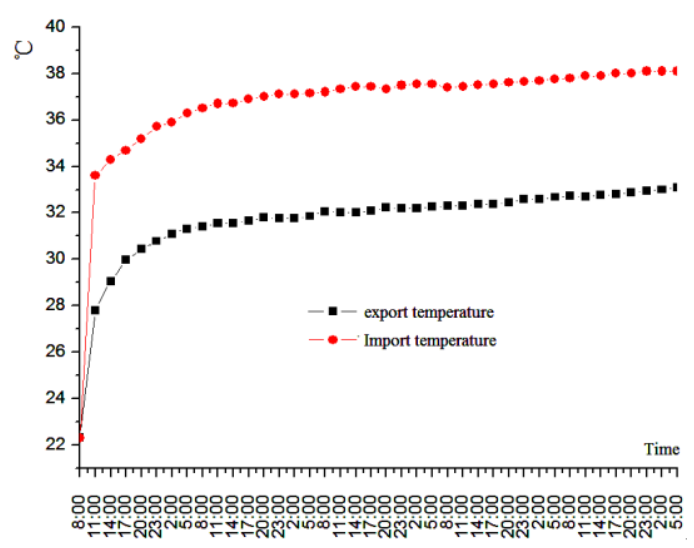

Figure 4 Import and export temperature variation of geothermal heat exchanger 


\section{Continuous working condition of heat removal test}

Buried pipe heat exchanger in water velocity $0.3 \mathrm{~m} / \mathrm{s}$ was selected as the experimental flow velocity. Test results are shown in Fig. $4 \sim$ Fig. 5.

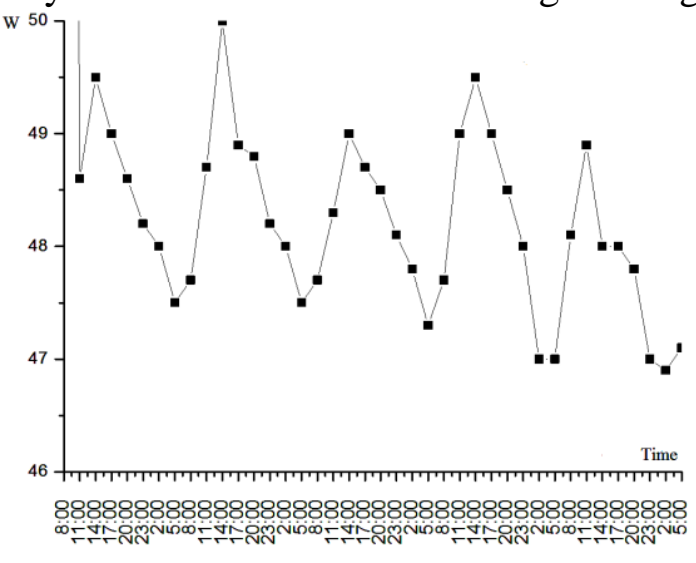

Figure 5 Unit well depth in heat variation of continuous running

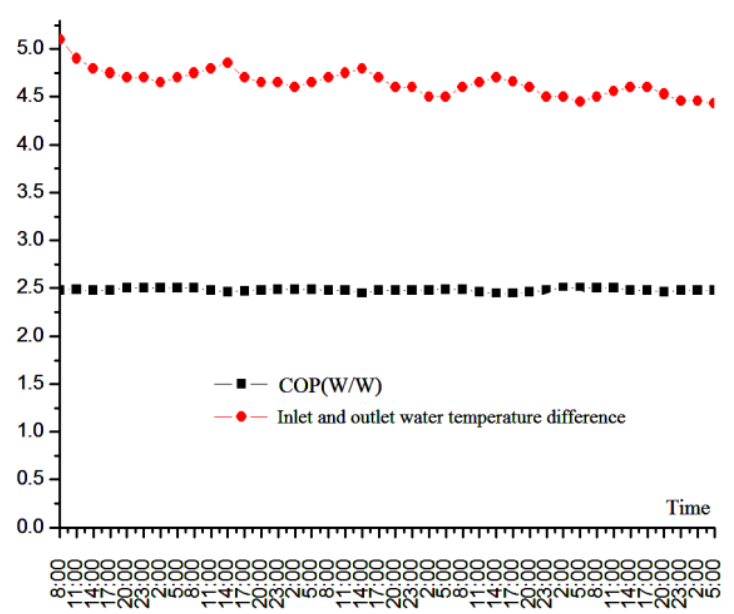

Figure 6 The COP and inlet and outlet water temperature variation in the system is run continuously

As can be seen, buried tube heat exchanger import water temperature and inlet and outlet water temperature difference tends to be stable with the system running time. Unit hole deep heat transfer and refrigeration system coefficient COP are reduced decreases when the flow velocity reduced decrease. Unit hole deep heat transfer compared with 1 day reduced $1.1 \mathrm{~W} / \mathrm{m}$ in 5 days. During the test, the average quantity of heat exchange for unit hole depth is $48.2 \mathrm{~W} / \mathrm{m}$. From Fig. 6, we can see that the stability for the return water temperature difference is about $4.5{ }^{\circ} \mathrm{C}$, average system COP of 2.16 .

\section{The intermittent heat removal condition test}

Working condition of intermittent operation of the system was tested on August 11 to 17.System switched on during the day, down in the evening. Under $0.3 \mathrm{~m} / \mathrm{s}$ velocity, the rate of system start-up and shut-down is 1:2, the test results are shown in Fig. $7 \sim$ Fig. 10.

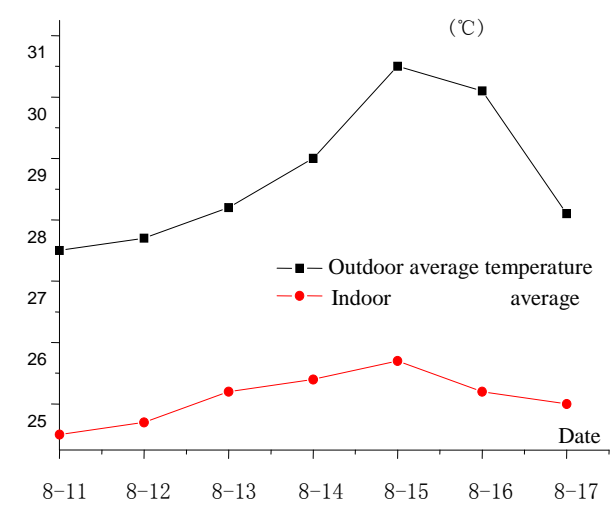

Figure 7 Indoor and outdoor temperature variation after run $8 \mathrm{~h}$ in the daytime

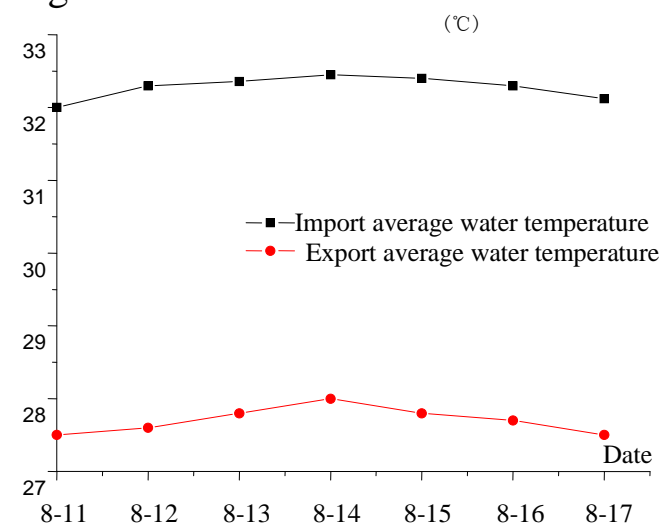

Figure 8 Import and export temperature of buried pipe after run $8 \mathrm{~h}$ in the daytime 


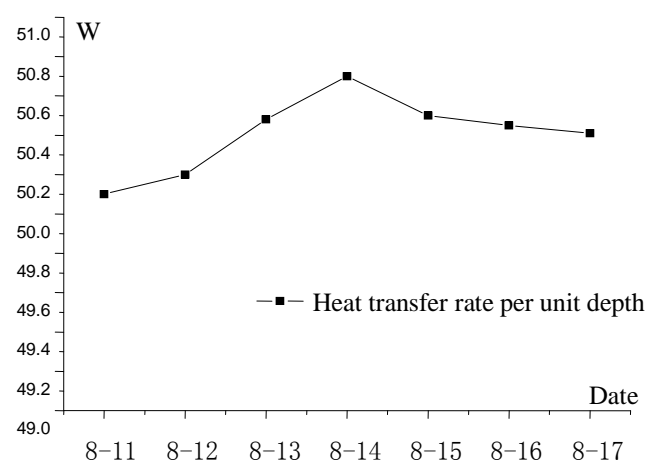

Figure 9 Quantity of heat exchange for unit holes depth after run $8 \mathrm{~h}$ in the daytime

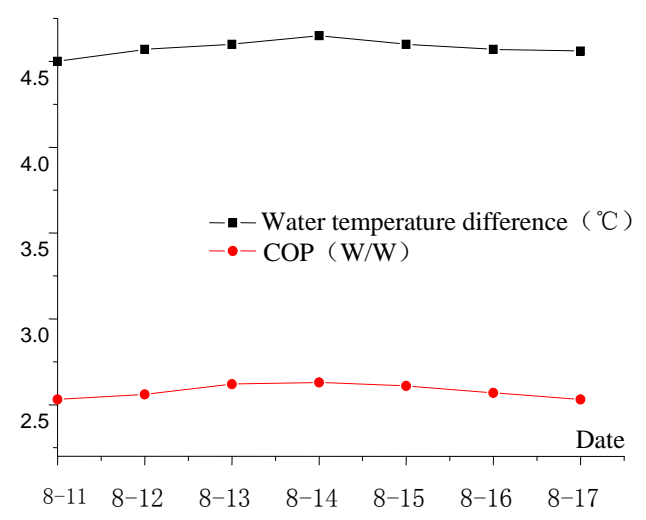

Figure 10 The system's COP and inlet and outlet water temperature difference after run 8 $\mathrm{h}$ in the daytime

It can be seen that quantity of heat exchange for unit holes depth and buried tube heat exchanger's water temperature changes greatly under test conditions. The maximum that average quantity of heat exchange for unit holes depth is $50.7 \mathrm{~W} / \mathrm{m}$ on August 14.And the minimum that average quantity of heat exchange for unit holes depth is $50.1 \mathrm{~W} / \mathrm{m}$ appear in August 11. Average quantity of heat exchange for unit holes depth is $50.4 \mathrm{~W} / \mathrm{m}$, the system COP is 2.57 on average.

\section{Operation simulation}

Although the mechanisms of heat transfer are the same, buried tube heat exchanger and heat transfer condition of the soil around are different in different seasons. The key problem of ground source heat pump system is that underground soil whether can keep the heat balance in the system running after some years. In this paper, the $\mathrm{k}-\varepsilon$ two-equation model was used to simulate the u-shaped tube fluid flow situation. Using three dimensional heat transfer model to simulate surrounding soil temperature of heat exchanger in system operation in 5 years. Simulation results are shown in Fig. 11.

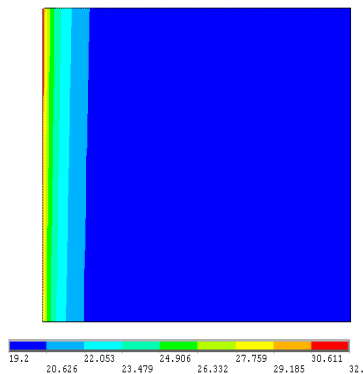

a

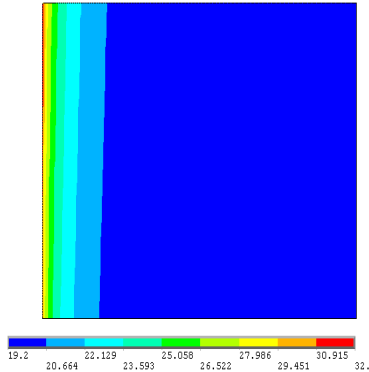

$\mathrm{b}$

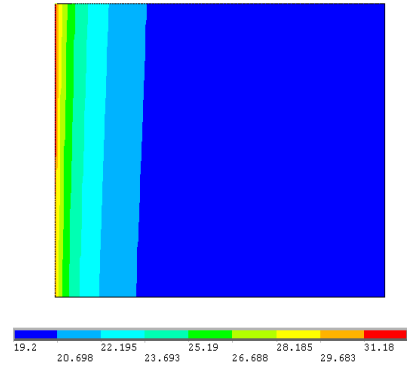

$\mathrm{c}$

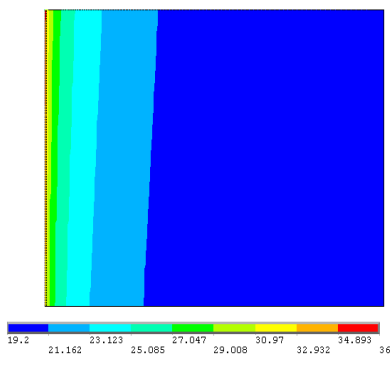

d

Figure 11 The soil temperature field variation of the system. (a. running after 1 year later. $b$. running after 2 year later. c. running after 4 year later. d. running after 5 year later)

It can be seen that soil temperature around the heat exchanger has increased after running some years. Soil temperature around the heat exchanger increased by $0.2^{\circ} \mathrm{C}$ after running 1 years later. Soil temperature around the heat exchanger increased by $0.9^{\circ} \mathrm{C}$ after running 5 years later. In areas similar with Hefei, therefore, the cooling load is greater than the heating load of the region. Simply 
using buried tube heat exchange system will lead to the underground soil thermal imbalance. And there is a phenomenon of heat accumulation.For the purpose of this project, the heat accumulation can be largely ignored.

\section{Conclusions}

In this paper, the experiment analyzed the condition of continuous and intermittent operation of each performance index in typical climatic conditions in the winter of Hefei, and simulated the change and recovery of soil temperature field around the buried tube heat exchanger of ground source heat pump system after 5-year operation. It turned out that the various operation parameters under the intermittent operation mode is better than continuous operation mode parameters of buried tube heat exchanger. Soil temperature around the heat exchanger increased by $0.9{ }^{\circ} \mathrm{C}$ after running 5 years later. Thus, for areas similar with Hefei where cooling load is greater than the heating load of typical hot summer and cold winter region, and underground existence of heat accumulation is weak.

\section{Acknowledgements}

This work was financially supported by the International Scientific and Technological Cooperation Program (No. 1503062012) and the Doctor Program of Anhui Jianzhu University (No. K10099).

\section{References}

1. Shuhong Li, Weihua Yang, Xiaosong Zhang, Soil temperature distribution around a U-tube heat exchanger in a multi-function ground source heat pump system, Applied Thermal Engineering, 2009, Vol.29 (17), pp.3679-3686.

2. Weibo Yang, Mingheng Shi, Guangyuan Liu, Zhenqian Chen, A two-region simulation model of vertical U-tube ground heat exchanger and its experimental verification, Applied Energy, 2008, Vol.86 (10), pp.2005-2012.

3. A.C. Lyman, R.A. Stephan, K.A. Thole, L.W. Zang, S.B. Memory, Scaling of heat transfer coefficients along louvered fins, Exp. Therm. Fluid Sci. 26 (2002) 547-563.

4. Hikmet Esen, Mustafa Inalli, ANN and ANFIS models for performance evaluation of a vertical ground source heat pump system, Expert Systems With Applications, 2010, Vol.37 (12), pp.8134-8147.

5. Yuehong $\mathrm{Bi}$, Lingen Chen, Chih $\mathrm{Wu}$, Ground heat exchanger temperature distribution analysis and experimental verification,Applied Thermal Engineering, 2001, Vol.22 (2), pp.183-189.

6. Gehlin, Signhild E A, Spitler, Jeffrey D,Effects of Ground Heat Exchanger Design Flow Velocities on System Performance of Ground Source Heat Pump Systems in Cold Climates,ASHRAE Transactions, 2015, Vol.121, pp.1U-8U.

7. E. Pulat, S. Coskun, K. Unlu, N. Yamankaradeniz, Experimental study of horizontal ground source heat pump performance for mild climate in Turkey, Energy 34 (9) (2009) 1284-1295. 